\title{
LETRAMENTOS DIGITAIS, INTERDISCIPLINARIDADE E APRENDIZAGEM DE LÍNGUA INGLESA POR ALUNOS DO ENSINO MÉDIO
}

\section{DIGITAL LITERACIES, INTERDISCIPLINARITY AND ENGLISH LANGUAGE LEARNING BY HIGH SCHOOL STUDENTS}

\section{Lucas Moreira dos Anjos-Santos* Raquel Gamero Telma Nunes Gimenez}

\section{RESUMO}

As tecnologias digitais fazem parte da vida contemporânea e sua apropriação criativa e potencialmente subversiva tem provocado transformações nos modos de produção do conhecimento e da informação. Tendo por base as concepções de letramentos digitais (SNYDER, 2009; BUZATO, 2009; MOITA LOPES, 2010) e de ensino de línguas comunicativo baseado em tarefas (BROWN, 2007; WILLIS, 1996), realizamos atividades de aprendizagem de língua inglesa por adolescentes, estudantes do ensino médio, em contexto de imersão. Por meio do projeto institucional Novos Talentos, financiado pela CAPES, planejamos e desenvolvemos uma semana de atividades em língua inglesa, envolvendo diferentes práticas letradas digitais, com vistas à interdisciplinaridade. Neste artigo apresentamos o arcabouço conceitual orientador das atividades, uma descrição das atividades realizadas em diferentes oficinas, bem como uma discussão sobre os papéis dos letramentos digitais no desenvolvimento de projetos interdisciplinares e ensino-aprendizagem de língua inglesa.

Palavras-chave: letramentos digitais; interdisciplinaridade; novos talentos; Ensino Médio.

\section{ABSTRACT}

Digital technologies are part of contemporary life and their creative and potentially subversive appropriation has provoked transformations in the ways knowledge and information are produced. Based on the concepts of digital literacies (SNYDER, 2009; BUZATO, 2009; MOITA LOPES, 2010) and on communicative task-based language teaching (BROWN, 2007; WILLIS, 1996), we developed activities for English learning by adolescents, high school students, in an immersion context. Through the institutional program "Novos Talentos", sponsored by CAPES, we planned and developed activities in English around different digital literacy practices aiming at an interdisciplinary work. In this article, we discuss the

\footnotetext{
* Monash University, Melbourne, Austrália. lucas.santos@monash.edu; Bolsista da CAPES - Proc. nº 0965120.; UENP/UEL, Cornélio Procópio, (PR), Brasil. raquelgamero.rg@gmail.com; UEL, Cornélio Procópio, (PR), Brasil. tgimenez@uel.br; CNPq - bolsa produtividade (Processo 308820/2011-8).
} 
theoretical framework foregrounding the activities, describe the activities developed for different workshops and discuss the roles digital literacies may have in the development of interdisciplinary projects and English teaching and learning.

Keywords: digital literacies; interdisciplinarity; "Novos Talentos", High School.

\section{INTRODUÇÃO}

A língua inglesa e as tecnologias digitais têm assumido papel cada vez mais importante no mundo contemporâneo. Autores como Moita Lopes (2005) e Graddol (2006) apontam para as interligações entre ambas, reforçadas mutuamente pela necessidade e facilidade de comunicação, especialmente após o advento da Internet. Parece inegável que os processos associados à globalização contemporânea têm contribuído para fortalecimento dessa interligação. Conforme muitos argumentam, esse é um processo ambíguo, nos quais tanto se invoca o discurso da inclusão quanto o da exclusão:

A exclusão digital tem sido uma das grandes preocupações de governos nos vários níveis no
Brasil e em várias partes do mundo. Mas quero argumentar aqui que a exclusão lingüística
precede a exclusão digital. Não basta dotarmos as escolas públicas de computadores: é ne-
cessário instrumentar alunos e professores para que possam operar em redes de comunicação
nas formas multisemióticas de produzir significado nas telas dos computadores. Isso envolve
saber agir em redes de comunicação em tarefas de letramento computacional, que é, sem dúvi-
da, um dos letramentos mais importantes atualmente. Tal letramento requer necessariamente
educação lingüística de qualidade na língua materna e no uso do inglês (MOITA LOPES,
2005, p.6-7)

De acordo com essa perspectiva, a aprendizagem de inglês na atualidade e a apropriação de práticas de letramento digital se tornam requisito fundamental para a cidadania. Propostas contemporâneas, como as "Orientações curriculares para o Ensino Médio - Línguas Estrangeiras Modernas" (BRASIL, 2006) reconhecem essa nova realidade e sinalizam para a necessidade de multiletramentos em sociedades altamente semiotizadas. Segundo aquele documento, os currículos que incorporam o letramento crítico como parte dos objetivos para se aprender uma língua estrangeira, partem do reconhecimento da interrelação entre as linguagens produzidas pelas novas tecnologias e o domínio da língua inglesa.

As novas tecnologias e as produções em língua inglesa têm possibilitado a emergência de diferentes gêneros textuais que circulam na esfera virtual. A produção e/ou compreensão desses gêneros textuais é permeada por processos de (re) configuração de práticas discursivas bastante consolidadas, ao mesmo tempo em que são atualizadas pelas características específicas das interações possibilitadas 
por meio das tecnologias digitais. Como bem aponta Marcuschi (2004), os desafios apresentados pelas práticas sociais de origem virtual devem ser estudados a fim de compreendermos as relações e papéis que diferentes protagonistas têm nesse espaço. Por outro lado, no contexto educacional faz-se necessário oportunizar espaços para discussão da necessidade do uso de tecnologias digitais como mediadoras de práticas sociais contemporâneas, a partir de atividades pedagógicas que viabilizam o uso dessas ferramentas de maneira crítica e criativa. Snyder (2009, p.43-44) sustenta:

\footnotetext{
Por ora, como professores, nós ainda estamos encarregados com a responsabilidade de encontrar maneiras inovadoras para incorporar os novos letramentos na prática de sala de aula. As habilidades e o conhecimento do letramento impresso são essenciais, mas não são suficientes para dar assistência aos jovens, ao passo que eles vivem suas vidas em uma sociedade de informação e rede.

$[\ldots]$

A responsabilidade dos educadores de letramento é proporcionar aos jovens oportunidades cuidadosamente planejadas para que eles aprendam como se tornar navegadores críticos no novo panorama do letramento em tempos digitais.
}

No entanto, a aprendizagem de inglês nas escolas regulares brasileiras ainda sofre de muitos males, como um grande número de alunos em sala de aula, poucos e inadequados recursos didáticos, carga horária mínima para a disciplina e professores com formação insuficiente para lidar com os contextos difíceis em que se encontram. Embora tenhamos presenciado melhorias pontuais e localizadas em algumas regiões, de modo geral, há um sentimento generalizado de que o aprendizado de inglês precisa melhorar.

Do mesmo modo que a língua inglesa tem se tornado cada vez mais presente, o uso de diferentes tecnologias digitais tem sido incorporado às mais diversas práticas sociais contemporâneas. As mudanças na organização, acesso e produção de informação e conhecimento têm sido marcadas pelas apropriações criativas e potencialmente subversivas de práticas letradas digitais pelos indivíduos (CASTELLS, 2000; 2007). Nesse contexto de crescentes transformações, práticas pedagógicas que busquem articular, por meio de projetos interdisciplinares, aprendizagem de línguas e letramentos digitais podem representar grandes desafios e colocar questionamentos quanto à natureza da aprendizagem (não) formal da língua inglesa. Baseados nas concepções de letramentos digitais (SNYDER, 2009; BUZATO, 2009; MOITA LOPES, 2010) e no ensino de línguas comunicativo baseado em tarefas (BROWN, 2007; WILLIS, 1996), temos por objetivo, neste artigo, relatar uma experiência de aprendizagem interdisciplinar de língua inglesa, a partir do uso de tecnologias digitais, por alunos do ensino médio, no âmbito do Programa "Novos 
Talentos", que será melhor descrito adiante. Para esse fim, apresentamos, inicialmente, o arcabouço teórico sobre tecnologias digitais e as relações entre letramentos digitais, interdisciplinaridade e aprendizagem de língua inglesa. Posteriormente, descreveremos brevemente o Programa financiado pela CAPES que possibilitou a oferta de 30 horas de imersão em língua inglesa para 60 estudantes do ensino médio na cidade de Londrina, bem como as oficinas planejadas para o que se denominou "English Immersion Week".

\section{AS TECNOLOGIAS DIGITAIS DE INFORMAÇÃO E COMUNICAÇÃO (TDIC) NA CONTEMPORANEIDADE: CONEXÕES OU EXCLUSÕES EM REDE?}

De acordo com Castells (2000), as tecnologias digitais de informação e comunicação têm mudado profundamente a sociedade em que vivemos. Essas mudanças vão desde a reestruturação do sistema capitalista para aumentar a acumulação de capital às transformações culturais das maneiras pelas quais as pessoas se relacionam. Não se trata de olhar para tais transformações como radicalmente positivas ou negativas, mas, sim, de analisá-las de modo a compreender como seus usos têm moldado outras práticas sociais na vida contemporânea. A análise, empreendida pelo autor, ressalta novas relações entre quem produz e quem consome informação e a lógica própria das TDIC, que convergem qualquer conhecimento para um sistema comum com alta capacidade (senão ilimitada) de armazenamento, acessibilidade e transformação.

No entanto, é necessário ressaltar que "[...] há grandes áreas do mundo e consideráveis segmentos da população que estão desconectados do novo sistema tecnológico (... $)^{1 \prime \prime}$ (CASTELLS, 2000, p. 52). Dessa forma, o uso e a apropriação das TDIC, por diferentes grupos da sociedade, dão-se de maneira seletiva e funcional e estruturam-se pela lógica econômica social vigente. Tendo por base tal panorama, este autor relaciona as transformações político-econômicas decorridas da Revolução da Tecnologia da Informação, como esse período é denominado pelo autor, ao fluxo de capitais, às organizações das empresas em redes, às novas formas de controle financeiro em nível global e às implicações para o mundo do trabalho.

Um novo meio tecnológico, quando emerge e é incorporado às práticas sociais de uma determinada comunidade, certamente influencia o modo como as pes-

\footnotetext{
1 Apesar de tal afirmação do autor ser de quase 12 anos atrás, no contexto brasileiro ainda é evidente que o acesso às novas tecnologias não atinge toda a população. A existência de políticas públicas que possibilitem o acesso ao uso de novas tecnologias tem, ao menos parcialmente, indicado uma universalização (conferir, por exemplo, o plano nacional de banda larga).
} 
soas se relacionam e seus modos de entender o mundo. Não partimos da ideia de que a tecnologia determina a sociedade, mas sim de que a tecnologia é constitutiva da sociedade. Os usos que determinados grupos fazem de diferentes tecnologias é que constituem espaços de transformação das relações sociais. Castells (2000) ressalta que a cultura eletrônica com sua capacidade de integrar diferentes linguagens, sejam elas verbais, visuais, sonoras ou corporais, estabelece outros modos de conhecer o mundo. Para o autor (2000, p. 369) "(a) rede Internet é a espinha dorsal da comunicação global mediada por computadores (CMC) dos anos 90, uma vez que liga gradativamente a maior parte das redes".

No entanto, Castells (2005) faz ressalvas sobre o que comumente é denominado de sociedade da informação ou do conhecimento. Para ele, a informação e o conhecimento sempre foram vitais em qualquer sociedade, e não somente na organização contemporânea. A diferença da sociedade atual é que sua base microeletrônica possibilitou novas formas de organização e distribuição dos conhecimentos. As redes que eram limitadas em função de aspectos geográficos, temporários e econômicos, passaram a possuir grande potencial e impacto mundial, numa compressão espaço-tempo, em função das redes digitais. De acordo com o autor:

A sociedade em rede, em termos mais simplistas, é uma estrutura social baseada em redes operadas por informação e tecnologia de comunicações baseadas na microeletrônica e nas redes digitais de computador que geram, processam, e distribuem informação com base no conhecimento acumulado nos nós das redes. (CASTELLS, 2005, p.7).

Não se trata de endeusar a sociedade em rede como um estágio superior de organização social a ser atingido, porque da mesma forma que seu potencial de inclusão é ilimitado, o contrário também se faz verdadeiro (BRAGA, 2010). Trata-se, pois, de compreender o mundo em que vivemos e de problematizarmos as consequências desse novo momento histórico.

A partir de uma análise da perda de credibilidade do poder público, causada por inúmeros escândalos pessoais e de corrupção em diferentes países e do papel da mídia de massa na construção desse efeito, Castells (2007) passa a refletir sobre o papel das novas formas de comunicação emergentes da internet, algumas já consolidadas, na difusão de novas perspectivas. O processo de produzir, disponibilizar via digitalização e de receber conteúdo construído por diferentes atores sociais é denominado de mass self-communication (ou comunicação de massa do eu).

É dentro desse cenário, que o autor constrói a posição de que a internet tem possibilitado novas plataformas de debate, discussão e transformação social por meio de suas características peculiares e da noção de contrapoder, que é entendido como "[...] as capacidades de atores sociais desafiarem e eventualmente mudarem 
as relações de poder institucionalizadas na sociedade ${ }^{2 \prime}$ (CASTELLS, 2007, p. 248). Nesse sentido, os movimentos sociais têm articulado suas práticas e ações sociais por meio da internet com as formas já conhecidas de resistência cultural. Portanto, esse movimento pode ser analisado a partir do entendimento das:

[...] dinâmicas históricas de contrapoder, como novas formas de mudança social e a emergência de políticas alternativas, usando a oportunidade oferecida pelas novas redes horizontais de comunicação da era digital que são a infraestrutura técnica e organizacional que são específicas da sociedade em redes. Portanto, não somente o espaço público se torna largamente definido no espaço da comunicação, mas este espaço é um terreno cada vez mais contestado, já que expressa uma nova era histórica em que uma nova forma de sociedade está nascendo, assim como todas as sociedades prévias, por meio de conflito, esforço, dor, e frequentemente violência ${ }^{3}$. (CASTELLS, 2007, p. 258)

A posição de Castells (2007) parece indicar que as TDIC e as práticas linguageiras, desenvolvidas a partir ou emergidas delas, são potencialmente propícias para o desenrolar da(s) arena(s) de debates sobre mudanças na sociedade. Desse ponto de vista, as TDIC não apenas incluem quanto podem expandir outras perspectivas.

Tendo por base esse breve panorama dos papéis das TDIC nas sociedades contemporâneas, defendemos que oportunidades de engajamento, por meio da língua inglesa e de diferentes tecnologias digitais, podem ser propiciadas a alunos advindos do contexto público de ensino haja vista o descompasso entre as práticas sociais contemporâneas e as práticas pedagógicas vigentes na rede pública de ensino.

\section{LETRAMENTOS DIGITAIS E APRENDIZAGEM DE LÍNGUA INGLESA}

Como apontado na seção anterior, as práticas sociais permeadas pelo uso de tecnologias digitais são crescentes na constituição do indivíduo contemporâneo. Enviar e-mails; acessar o facebook e responder mensagens de amigos, comentar em fotos, compartilhar vídeos e fotos com legendas diversas; assistir e/ou postar um vídeo no youtube e reagir às postagens que apreciam os diferentes vídeos do youtu-

2 "[...] the capacity by social actors to challenge and eventually change the power relations institutionalized in society" (nossa tradução).

3 "[...] historical dynamics of counter-power, as new forms of social change and alternative politics emerge, by using the opportunity offered by new horizontal communication networks of the digital age that is the technical and organizational infrastructure that is specific of the network society. Therefore, not only public space becomes largely defined in the space of communication, but this space is an increasingly contested terrain, as it expresses the new historical stage in which a new form of society is being given birth, as all previous societies, through conflict, struggle, pain, and often violence." (nossa tradução). 
$b_{e}$, buscar informações em fóruns sobre como realizar determinada atividade; ler e avaliar a opinião de diferentes consumidores na web sobre produtos que queremos adquirir; reclamar e protestar contra danos causados ao consumidor nos sites da empresa fornecedora do produto; acompanhar e solicitar informações de órgãos governamentais sobre os gastos públicos de determinada área/setor são algumas das muitas ações sociais que podemos realizar mediatizados pelo uso das diferentes TDIC.

Essa breve lista de ações demonstra, a título de exemplificação, as diferentes demandas comunicativo-sociais propiciados pelo engajamento dos indivíduos em redes interconectadas da Internet. Conforme apontam Leu, Kinzer, Coiro e Cammack (2004, p. 1571):

Embora esteja claro que muitos novos letramentos estão emergindo rapidamente, cremos que os mais essenciais do ponto de vista da escola se agrupam ao redor da Internet e permitem aos alunos explorar as extensas TICs que se tornaram disponíveis em um ambiente online e conectado. Na era da informação, acreditamos ser essencial preparar os alunos para estes novos letramentos porque eles são centrais para o uso da informação e aquisição de conhecimento. ${ }^{4}$

Analogamente, presenciamos um feixe de possibilidades de prática real do uso da língua inglesa (doravante LI) em diversos contextos por meio do acesso às diferentes práticas letradas digitais. A aprendizagem de LI pode ser potencialmente ampliada a partir da incorporação do uso de TDIC nas práticas pedagógicas formais (no caso da escola pública, por exemplo) assim como em práticas de aprendizagem em contextos não formais (a necessidade de compreender e usar a língua inglesa para jogar um jogo de videogame, por exemplo).

Planejar, produzir e implementar práticas pedagógicas para a aprendizagem de LI a partir do uso de TDIC se mostram um dos grandes desafios dos professores de LI no século XXI. No entanto, uma compreensão crítica e responsiva dos papéis dos letramentos digitais na sociedade contemporânea se faz premente para oportunizar a construção de projetos pedagógicos teórica e reflexivamente embasados.

Ancorados em Moita Lopes (2010), defendemos que os letramentos digitais são práticas sociais situadas e

envolvem a participação colaborativa de atores sociais localizados socio-histórico-culturalmente na construção conjunta de significados, mediada por instrumentos multisemióticos (textos, imagens, vídeos, sons etc.), em comunidades de práticas (Wenger, 1998) no mundo

4 "While it is clear that many new literacies are emerging rapidly, we believe the most essential ones for schools to consider cluster around the Internet and allow students to exploit the extensive ICTs that become available in an on-line, networked environment. In an information age, we believe it becomes essential to prepare students for these new literacies because they are central to the use of information and the acquisition of knowledge" (nossa tradução). 
digital. A tela do computador deixa de ser somente um local onde se busca informação e passa a ser principalmente um lugar de construção, de disputa, de contestação de significados. Ou seja, passa a ser um espaço de encontros múltiplos com outros atores sociais, aumentando e transformando nossos repertórios de sentidos infinitamente [...] (MOITA LOPES, 2010, p. 398).

Analogamente, a partir das concepções que a sociedade mantém sobre TDIC, Buzato (2006) convida-nos a discutir o papel que as TDIC poderiam ter na educação. Segundo ele, muitas vezes, ao pensar na incorporação de recursos tecnológicos na educação, focalizamos os resultados que queremos e os objetivos que podem ser atingidos, sem questionarmos as relações sociais mais amplas que permeiam os usos de tais TDIC.

$\mathrm{O}$ autor advoga que não devemos entender a tecnologia nem como determinante dos processos da sociedade nem como determinada pelos usos que fazemos dela. A tecnologia transforma a sociedade e, é, por ela, transformada. As relações entre tecnologia e sociedade são constitutivas de um processo ininterrupto de fatores que se coadunam ou se embatem na transformação de práticas sociais e linguageiras. Em vista disso, as diferentes práticas sociais constitutivas da sociedade, nos levam ao conceito de letramentos que:

[...] são práticas sociais e culturais que têm sentidos específicos e finalidades específicas dentro de um grupo social, ajudam a manter a coesão e a identidade do grupo, são aprendidas em eventos coletivos de uso da leitura e da escrita, e por isso são diferentes em diferentes contextos sócio-culturais (BUZATO, 2006, p.5).

Baseado nessa concepção de letramento, Buzato (2006) defende que os letramentos propiciados pelo meio digital não devem ser apartados dos demais. A articulação entre diferentes tipos de letramentos é condição para participação efetiva e criativa nas diversas situações e esferas de atividade. Decorrente de uma visão sociológica de mundo, em que incluir é muito mais do que somente dar acesso, o autor define letramentos digitais como "redes complexas e heterogêneas que conectam letramentos (práticas sociais), textos, sujeitos, meios e habilidades que se agenciam, entrelaçam, contestam e modificam mútua e continuamente, por meio, virtude ou influência das TIC" (BUZATO, 2009, p. 22).

A adesão a tais perspectivas sobre letramentos digitais (MOITA LOPES, 2010; BUZATO, 2009) implica a produção de propostas pedagógicas situadas que visem ao desenvolvimento de capacidades cognitivas, sociais, linguísticas, multimodais e políticas dos aprendizes de língua inglesa. Transitar entre diferentes áreas do saber, se posicionar diante dos discursos produzidos em diferentes esferas de ativi- 
dades e produzir 'novos' discursos na arena social que configura a web 2.0 é condição essencial para o desenvolvimento de uma consciência e cidadania planetária. Nosso papel, enquanto professores de língua inglesa, em tempos contemporâneos de constante mudança é "propiciar aos mais jovens oportunidades cuidadosamente planejadas para que eles aprendam como se tornar navegadores críticos no novo panorama do letramento em tempos digitais" (SNYDER, 2009, p.44). Neste sentido, a inter e a transdisciplinaridade se colocam como eixos norteadores da educação para a linguagem.

\section{ESTABELECENDO PONTES ENTRE INTERDISCIPLINARIDADE, LETRAMETOS DIGITAIS E APRENDIZAGEM DE LÍNGUA INGLESA}

Nas últimas décadas o discurso da interdisciplinaridade tem sido incorporado aos documentos prescritivos como um componente integrador, facilitador e motivador do ensino (BRASIL, 1998; 2006). No caso do ensino médio, em particular, essa proposta tem ganhado força, especialmente com a publicação das Diretrizes Curriculares para o Ensino Médio (BRASIL, 2012) e com a matriz orientadora do Exame Nacional do Ensino Médio (ENEM).

Há também uma ampla discussão sobre as diversas maneiras de se compreender ensino-aprendizagem em perspectiva interdisciplinar (LEFFA, 2006). Nossa compreensão da interdisciplinaridade e de seu papel, dentro da proposta didático-pedagógica que ora descrevemos, é a de que se trata da articulação entre diferentes áreas do conhecimento, mediadas pela linguagem, para promover a conscientização de desenvolvimento crítico e de contato/acesso a diferentes esferas 'sociais possibilitadas pelas TDIC.

Desta forma, a proposta interdisciplinar busca interação entre diferentes disciplinas com foco em um determinado objeto (LEFFA, 2006), mas, na verdade, sua base está na formação do cidadão, de modo que o projeto educacional interdisciplinar propõe em primeiro plano uma ligação entre o indivíduo e a sociedade (SEVERINO, 1998). Ou seja, o conhecimento possibilita às "novas gerações a intencionalidade da cidadania, de modo a poder garantir a tessitura democrática de suas relações sociais." (p. 42).

Tendo em vista que o contexto de desenvolvimento das atividades agrupadas sob a denominação de "English immersion Week" é ímpar, uma concepção disciplinar nos pareceu inadequada e limitadora, uma vez que "as disciplinas têm uma 
tendência muito forte em delimitar o saber, criando uma espécie de territorialização do conhecimento [...]" (LEFFA, 2006, p. 32). Por conseguinte, nossa sociedade mais e mais demanda do cidadão a articulação de conhecimentos e agentividade e o inglês tem sido ponte dessa articulação, em especial pelo avanço das TDIC e pelo advento da internet. Assim, pareceu-nos mais relevante "refletir sobre a necessidade e a maneira de como desterritorializar o conhecimento necessário para explicar um processo extremamente complexo como é a aprendizagem da língua estrangeira." (LEFFA, 2006, p. 32).

O subprojeto ora tratado buscou ampliar as possibilidades de alunos do ensino médio em escolas públicas, no tocante a suas possibilidades de ação social e à sua conscientização a respeito do potencial empoderador das TIDCs. Segundo Garcia e Leffa (2010, p. 329), essas tecnologias são empoderadoras por propiciar "novas formas de acesso à informação e novos estilos de raciocínio e de conhecimento, amplificando uma profunda mutação do saber, prolongando determinadas capacidades cognitivas humanas - memória, imaginação, percepção".

Se, por um lado, o uso de tecnologias faz parte do cotidiano dos nossos alunos, por outro, seu uso se restringe a determinadas ferramentas, em especial as voltadas ao entretenimento. Assim, em uma tentativa de articular o objeto de ensino ao contexto social, levando em conta as necessidades do público-alvo, a abordagem interdisciplinar adotada possibilitou o distanciamento da clássica fragmentação dos conhecimentos que orientam a formação do cidadão. No planejamento, consideramos a realidade dos alunos envolvidos - em fase de decisão sobre que rumos tomar a partir da conclusão do ensino médio, em especial a escolha do curso superior no vestibular - e a necessidade de conscientização dos papéis assumidos pelo inglês na sociedade contemporânea.

Ao termos a oportunidade de organização e planejamento de uma atividade para alunos de ensino médio da escola pública, tomamos como orientação os referenciais sobre letramentos digitais e a possibilidade de rompimento com um planejamento estritamente disciplinar para propor oficinas que possibilitassem ao aluno vivenciar a língua inglesa em contextos significativos. Para isso, optamos por proporcionar um contexto de imersão durante o período de férias escolares, condição essa possibilitada pelo financiamento advindo da CAPES, por meio do "Programa de Apoio a Projetos Extracurriculares: Investindo em Novos Talentos da Rede de Educação Pública para Inclusão Social e Desenvolvimento da Cultura Científica", por nós denominado simplesmente de "Novos Talentos." 


\title{
4. O PROGRAMA NOVOS TALENTOS/UEL
}

O programa Novos Talentos é uma iniciativa desenvolvida pela Coordenação de Aperfeiçoamento de Pessoal de Nível Superior (CAPES). O primeiro edital foi lançado em junho de 2010 e almejava, de acordo com o site do programa,

\begin{abstract}
apoiar propostas para realização de atividades extracurriculares para professores e alunos da educação básica - tais como cursos, oficinas ou equivalentes - que ocorram no período de férias das escolas públicas e/ou em horário que não interfira na frequência escolar. As atividades devem valorizar espaços inovadores, como dependências de universidades, laboratórios e centros avançados de estudos e pesquisas, museus e outras instituições, inclusive empresas públicas e privadas, visando ao aprimoramento e à atualização do público-alvo e a melhoria do ensino de ciências nas escolas públicas do país.
\end{abstract}

A Universidade Estadual de Londrina (UEL) submeteu uma proposta intitulada "Formação de professores e alunos da educação básica: oportunidades, prática, troca de saberes/vivências, estímulo à criatividade e à aproximação com os desafios postos por problemas da sociedade globalizada". Em 2011 este projeto contemplou quatro subprojetos:

1. Aprimorando novos talentos em Biologia

2. Treinamento de professores do ensino fundamental em Software Livre e Jogos Didáticos de Computador

3. Para inserção em um mundo globalizado: utilizando recursos tecnológicos no ensino e aprendizagem de inglês

4. O estudo de ciências morfológicas para a educação básica

Esses subprojetos ofertaram oficinas (algumas para professores e alunos e outras apenas para professores). Para facilitar a participação, essas atividades deveriam ser desenvolvidas em período não letivo. $O$ projeto relativo à língua inglesa, proposto pelo Departamento de Letras Estrangeiras Modernas (LEM), ofertou oficina de 40 horas, intitulada "Ferramentas tecnológicas para o desenvolvimento profissional e ensino-aprendizagem de língua inglesa" para professores da rede pública de Londrina e região. Para a oficina foi produzido um material didático intitulado "Connecting Ide@s: tools for teaching English in a contemporary society", cujo propósito foi o de auxiliar os facilitadores na orientação a professores sobre como articular a internet no ensino de inglês, com ênfase nos gêneros digitais (GAMERO; EL KADRI; GIMENEZ, 2012). 
Em 2012, o projeto foi prorrogado e novamente foram ofertadas as oficinas nas áreas de Histologia, Genética e Inglês. Além daquela voltada para a formação tecnológica de professores de inglês, incluímos na reformulação a oferta de oficinas também para alunos do ensino médio. Em contato com o Núcleo Regional de Educação de Londrina, parceiro da iniciativa, foram selecionados 60 estudantes de 12 escolas públicas. Enquanto a atividade para os professores focalizava aspectos metodológicos e de aprendizagem de línguas, a dos alunos tinha como objetivo oportunizar a prática da língua inglesa em contextos significativos, i.e, contato com possíveis áreas de formação profissional.

\subsection{A semana de imersão em inglês "English Immersion Week"}

A semana de imersão em inglês foi organizada em torno de áreas do conhecimento, de modo a permitir um trabalho interdisciplinar. As cinco grandes áreas escolhidas foram: Letras, Física, Meio-Ambiente, Biologia e Artes e História. A escolha das áreas se deu a partir das condições de interação do departamento proponente (LEM) com os demais centros e departamentos da universidade no período da imersão. A partir dessas áreas, planejamos ${ }^{5}$ e implementamos oficinas que articulassem a aprendizagem de inglês e o uso de diferentes tecnologias digitais - com a finalidade de expor esses participantes ao maior número de ferramentas possível,

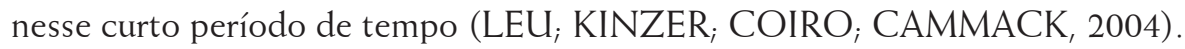

$\mathrm{O}$ quadro a seguir apresenta um panorama das atividades desenvolvidas na semana.

Quadro 1. Panorama do curso de imersão

\begin{tabular}{|c|c|c|c|c|c|}
\hline $\begin{array}{c}\text { Horário } \\
\text { previsto }\end{array}$ & Segunda & Terça & Quarta & Quinta & Sexta \\
\hline $\begin{array}{c}\text { 08:00 } \\
-09: 00\end{array}$ & Recepção & Recepção & Recepção & Recepção & Recepção \\
\hline $\begin{array}{c}\text { 09:00 - } \\
\text { 09:45 }\end{array}$ & $\begin{array}{c}\text { WORKSHOP 1: } \\
\text { Sharing personal } \\
\text { information } \\
\text { WORKSHOP 1: }\end{array}$ & $\begin{array}{c}\text { Wverything } \\
\text { started with the } \\
\text { BIG BANG }\end{array}$ & $\begin{array}{c}\text { WORKSHOP 1: } \\
\text { The environ- } \\
\text { ment and you }\end{array}$ & $\begin{array}{c}\text { WORKSHOP 1: } \\
\text { Do you know } \\
\text { yourself inside } \\
\text { out? }\end{array}$ & $\begin{array}{c}\text { WORKSHOP 1: } \\
\text { Museum studies }\end{array}$ \\
\hline
\end{tabular}

5 Em função do tempo disponível esse planejamento foi realizado apenas pelos responsáveis pela oficina. Os workshops foram oferecidos por alguns participantes do projeto, por duas alunas da pós-graduação, em nível de mestrado e por uma English Teacher Assistant, vinculada à Fulbright, que trabalhava no Departamento de Letras Estrangeiras Modernas naquele momento. 


\begin{tabular}{|c|c|c|c|c|c|}
\hline $\begin{array}{l}9: 45- \\
10: 00\end{array}$ & coffee break & coffee break & coffee break & coffee break & coffee break \\
\hline $\begin{array}{l}10: 00- \\
10: 45\end{array}$ & $\begin{array}{l}\text { WORKSHOP 2: } \\
\text { What do you } \\
\text { know about } \\
\text { Languages? }\end{array}$ & $\begin{array}{c}\text { WORKSHOP 2: } \\
\text { Things happen } \\
\text { for a reason }\end{array}$ & $\begin{array}{l}\text { WORKSHOP 2: } \\
\text { Let's talk about } \\
\text { sustainable } \\
\text { agronomy }\end{array}$ & $\begin{array}{l}\text { WORKSHOP 2: } \\
\text { Curiosities } \\
\text { about our body }\end{array}$ & $\begin{array}{l}\text { WORKSHOP 2: } \\
\text { Do you know } \\
\text { how to read? } \\
\text { Talking about } \\
\text { expression }\end{array}$ \\
\hline $\begin{array}{l}10: 45- \\
11: 30\end{array}$ & $\begin{array}{l}\text { WORKSHOP 3: } \\
\text { Let's have some } \\
\text { fun? }\end{array}$ & $\begin{array}{c}\text { WORKSHOP 3: } \\
\text { Machinery } \\
\text { mysteries }\end{array}$ & $\begin{array}{l}\text { WORKSHOP 3: } \\
\text { Let's have some } \\
\text { fun? }\end{array}$ & $\begin{array}{l}\text { WORKSHOP 3: } \\
\text { Let's have some } \\
\text { fun? }\end{array}$ & $\begin{array}{c}\text { WORKSHOP 3: } \\
\text { Let's have } \\
\text { some fun? }\end{array}$ \\
\hline $\begin{array}{l}11: 30- \\
12: 00\end{array}$ & $\begin{array}{l}\text { Follow up - } \\
\text { everybody }\end{array}$ & $\begin{array}{l}\text { Follow up - } \\
\text { everybody }\end{array}$ & $\begin{array}{l}\text { Follow up - } \\
\text { everybody }\end{array}$ & $\begin{array}{l}\text { Follow up - } \\
\text { everybody }\end{array}$ & $\begin{array}{l}\text { Apresentação } \\
\text { dos trabalhos }\end{array}$ \\
\hline $\begin{array}{c}12: 00- \\
13: 00\end{array}$ & Almoço no R. U & Almoço no R. U & Almoço no R. U & Almoço no R. U & Almoço no R. U \\
\hline $\begin{array}{c}14: 00- \\
15: 30\end{array}$ & $\begin{array}{l}\text { Visita à Bibliote- } \\
\text { ca Central }\end{array}$ & $\begin{array}{c}\text { Visita ao Labora- } \\
\text { tório de física }\end{array}$ & $\begin{array}{c}\text { Visita à } \\
\text { fazenda-escola }\end{array}$ & $\begin{array}{c}\text { Visita ao museu } \\
\text { de anatomia }\end{array}$ & $\begin{array}{c}\text { Visita ao museu } \\
\text { histórico de } \\
\text { Londrina }\end{array}$ \\
\hline $\begin{array}{c}15: 30- \\
17: 00\end{array}$ & $\begin{array}{l}\text { Hands on: work- } \\
\text { ing on a project }\end{array}$ & $\begin{array}{l}\text { Hands on: work- } \\
\text { ing on a project }\end{array}$ & $\begin{array}{c}\text { Hands on: } \\
\text { working on a } \\
\text { project }\end{array}$ & $\begin{array}{l}\text { Hands on: work- } \\
\text { ing on a project }\end{array}$ & $\begin{array}{c}\text { Encerramento } \\
\text { do evento }\end{array}$ \\
\hline
\end{tabular}

Conforme apresentado inicialmente, o ensino da língua inglesa (LI) nessa proposta seguiu a metodologia do ensino de línguas tendo por base os multiletramentos e propostas de ensino voltado para a comunicação e baseado em tarefas (BROWN, 2007; WILLIS, 1996) com uso da LI em todas as atividades desenvolvidas, embora tenha havido flexibilidade quanto ao uso de diferentes metodologias e técnicas de ensino nos diferentes workshops. As atividades planejadas tiveram como preocupação transversal o desenvolvimento da consciência crítica para a cidadania.

A concepção de abordagem comunicativa de ensino de línguas adotada na produção das atividades foi a de que a aprendizagem de uma língua se dá primariamente a partir do engajamento do aluno em situações comunicativas autênticas e significativas para o uso da língua (BROWN, 2007). O princípio fundamental da abordagem comunicativa é a de que aprender uma língua é aprender a comunicar-se na referida língua. Conforme aponta Larsen-Freeman (2000, p.128):

O objetivo [do ensino comunicativo de línguas] é permitir aos alunos comunicarem-se na língua alvo. Para fazer isso os alunos precisam conhecer as formas linguísticas, os significados e suas funções. Eles precisam saber que diferentes formas podem ser usadas para desempenhar uma função e que também uma única forma pode geralmente servir a uma variedade de 
funções. Eles devem ser capazes de escolher, entre essas, a forma mais apropriada, dado o contexto social e os papéis dos interlocutores. Eles também devem ser capazes de gerenciar o processo de negociação de sentidos com seus interlocutores. ${ }^{6}$

Analogamente, o ensino de línguas comunicativo baseado em tarefas que guiou a produção das atividades, toma como pressuposto que as tarefas comunicativas são atividades que levam os alunos a compreender, produzir ou interagir na língua inglesa com o enfoque primário nos significados construídos e emergidos na interação, ao invés da forma usada (NUNAN, 1989; WILLIS, 1996). Na produção das atividades, entendíamos como tarefa "uma atividade comunicativa orientada por um objetivo com um resultado específico, onde a enfase é na troca de significados e não na produção de formas linguísticas específicas ${ }^{711}$ (WILLIS, 1996, p. 36).

A concepção de ensino comunicativo baseado em tarefas (NUNAN, 1989; BROWN, 2007; WILLIS, 1996) permitiu aos professores que produziram as atividades para os workshops que operacionalizarem diferentes atividades para a aprendizagem de língua inglesa. Essas concepções se subordinavam às preocupações mais amplas ligadas aos debates sobre letramentos digitais: o uso das tecnologias digitais e o engajamento em práticas letradas digitais como forma de negociação, contestação e produção de outros discursos sobre e no mundo de forma crítica e criativa (SNYDER, 2009; BUZATO, 2006; BRAGA, 2010; MOITA LOPES, 2010).

Com essa finalidade, os participantes foram divididos em equipes de aproximadamente cinco alunos, para facilitar o trabalho nos projetos e a cada dia eram alocados em diferentes formações para os workshops, que recebiam até 20 alunos. Cada grupo de 20 alunos participava de todos os workshops ofertados no dia, em um sistema de revezamento. Desta forma, todos os alunos tiveram a oportunidade de participar de todos os workshops.

Todas as manhãs os participantes eram reunidos em uma sala para as instruções do dia, retomada do conteúdo e atividades desenvolvidas no dia anterior. Essas retomadas eram feitas em forma de breaking the ice activities, tais como: qual é a música; balloon war; people bingo e movie songs.

Esses workshops eram organizados por eixo; sendo assim, as atividades da segunda-feira foram Sharing personal information, What do you know about Languages? e Let's

6 "The goal is to enable students to communicate in the target language. To do this students need knowledge of the linguistic forms, meanings, and functions. They need to know that many different forms can be used to perform a function and also that a single form can often serve a variety of functions. They must be able to choose from among these the most appropriate form, given the social context and the roles of the interlocutors. They must also be able to manage the process of negotiating with their interlocutors." (nossa tradução)

7 "a goal-oriented communicative activity with a specific outcome, where the emphasis is on exchanging meanings not producing specific language forms." (nossa tradução). 
bave some fun? Essas atividades giraram em torno do eixo de Letras, com foco em informações pessoais, integração entre os grupos, apresentação de ferramentas tecnológicas de aprendizagem de línguas e discussão crítica sobre a importância do aprendizado de línguas estrangeiras. Dentro dessas propostas, foram trabalhadas desde questões elementares de língua até questões de segurança e proteção de informações pessoais na rede.

$\mathrm{Na}$ terça-feira o eixo temático foi a Física, Química e Ciências da Computação trabalhado nos workshops Everything started with the BIG BANG. Things bappen for a reason e Machinery mysteries. As atividades propostas trabalharam respectivamente com conhecimentos gerais sobre astronomia mediados pela música e pela navegação na internet (youtube, enciclopédia online e websites), produziram uma reação química e exploraram a robótica, trabalhando o vocabulário e jogando um vídeo bingo.

Na quarta-feira, o eixo foi Meio-Ambiente e Agronomia, com os workshops: The environment and you, Let's talk about sustainable agronomy e Let's bave some fun? $\mathrm{O}$ foco das atividades da quarta-feira foi o critical awareness, de modo que as atividades priorizaram a produção oral, a interação e o posicionamento crítico dos alunos. Houve a integração das discussões entre os workshops 1 e 2 no sentido de mostrar aos alunos que a economia e o meio ambiente estão interconectados. Algumas das ferramentas tecnológicas utilizadas para mediar as discussões foram vídeos e websites sobre os assuntos abordados, com essas tentativas priorizamos pelo uso de instrumentos multisemióticos, conforme aponta Moita Lopes (2010), um lugar para contestação dos significados pré-existentes. $\mathrm{O}$ uso da projeção de imagens também foi uma estratégia de ensino da língua inglesa nesses espaços.

$\mathrm{Na}$ quinta-feira, o eixo temático foi Biologia e Anatomia, de modo que as atividades desenvolvidas no workshop Do you know yourself inside out? seguiram uma abordagem lexical (ASHER, 1969) e focaram na apresentação de léxico referente ao corpo humano e de situações de uso desse léxico. Nesta atividade, também se lançou mão de estratégias do método Total Pbysical Response (BROWN, 2007) para fixar o conteúdo lexical ensinado, vídeos para ilustrar e reforçar o conteúdo e recorreu a imagens para identificação de léxico e evitar a necessidade de tradução constante dos alunos. A liberdade para que cada encarregado de workshop desenvolvesse duas atividades lançando mão de diferentes técnicas/métodos de ensino seguiu a proposta de Kumaravadivelu (2001) de superar a adoção de um método único.

No segundo workshop, Curiosities about our body, a estratégia empregada foi a abordagem lexical, priorizando atividades de compreensão e produção oral e recorrendo a uma atividade lúdica (the taste game) para explorar na prática o conteúdo 
interdisciplinar enfocado (os cinco sentidos). O terceiro workshop, de caráter mais descontraído, retomou/apresentou os elementos lexicais abordados nos dois outros workshops, também em uma perspectiva lúdica.

Por fim, na sexta-feira, o eixo temático foi das Artes e História. Assim, o workshop What's a museum? teve como objetivo principal preparar os alunos para a visita que fariam ao museu municipal no final do dia, guiando os a essa prática social de modo consciente. O segundo workshop, Do you know how to read? Talking About Expression, tinha como fio condutor a conscientização para a leitura de imagens e de sua importância na sociedade contemporânea. Nesse workshop foram exploradas questões de ideologia, identidade pessoal e conhecimentos gerais de arte relacionados aos tópicos mencionados. Os alunos também fizeram neste workshop um tour virtual a diferentes museus de artes do mundo. Para concluir os workshops os alunos participaram de mais um Let's bave some fun?, jogando Image and Action, como atividade de wrap-up. Por intermédio desses workshops, visávamos criar espaços para que os alunos pudessem compreender que somos seres sócio-historicamente constituídos e que o outro exerce papel fundamental em nossas formas de comunicação e também de significação do/no mundo, e desse modo, tomar consciência de que projetam imagens/representações de si para o outro, seja intencional ou intuitivamente.

Com essas propostas de workshops ${ }^{8}$, buscávamos propor maneiras para incorporar os novos letramentos no ensino de LI nesse contexto, de modo a ofertar atividades cuidadosamente planejadas sob o viés crítico, em especial no que remete à navegação e ao uso de novas tecnologias (SNYDER, 2009), empregando essas ferramentas não apenas como forma de letramento digital, tendo em vista que muitos já conheciam e eram usuários das mesmas, mas também explorando seu teor motivador e em muitos momentos lúdico. Outro fator a se ressaltar por seu potencial motivador é a questão de desenvolver atividades de ciências aplicadas, por exemplo, as reações químicas exploradas na produção do vulcão. Desse modo, o conhecimento deixa de ter apenas teórico, e passa a ter finalidade e aplicabilidade no cotidiano, aproximando o ensino da realidade temporal e socialmente situada desses alunos (GEE, 2004; YOUNG, 2011).

Além das atividades de breaking the ice e dos workshops, os alunos fizeram visitas a diferentes departamentos da universidade que se disponibilizaram a demonstrar algumas de suas atividades. Assim, esses alunos visitaram a Biblioteca Central, os

8 Todas as atividades desenvolvidas para Imersão bem como as atividades usadas nas oficinas de educação continuada com os professores estão disponíveis por meio da publicação "Teaching and Learning English in Digital Times: Suggested workshop materials", disponível para download em < http://www.uel.br/ programas/novostalentos/pages/livro-teaching-and-learning-english.php> 
Laboratórios de Física, a Fazenda Escola, o Laboratório e o Museu de Anatomia e o Museu Histórico de Londrina.

Durante algumas dessas visitas foi possível estabelecer relações entre as diversas áreas do conhecimento exploradas e a necessidade do conhecimento da LI para essas áreas, como forma de acesso a conhecimentos (em diversos aparelhos do laboratório de física as instruções estavam em LI) como também para projeção profissional (os professores de física relataram aos alunos que a disseminação de suas pesquisas se dá em LI).

Ao longo da semana, esses alunos participaram de uma gincana, na qual algumas das atividades, seja de breaking the ice, seja nas atividades finais propostas nos workshops e também no projeto final de cada equipe, estavam sendo pontuadas. Assim, ao final da semana, uma das equipes seria vencedora. Com esta gincana buscávamos motivar os alunos a se engajarem nas atividades de modo a se responsabilizarem por si e por seus colegas de equipe, criando assim um senso de pertencimento e coletividade nos grupos.

Convergentes com a proposta didática de interrelação entre a aprendizagem de LI, o uso de tecnologias digitais e o diálogo interdisciplinar para despertar consciência crítica para a cidadania desses alunos inseridos nessa sociedade contemporânea lançamos mão dos nossos repertórios profissionais (incluindo os arcabouços teóricos) e de instrumentos multisemióticos (MOITA LOPES, 2010), em que buscávamos transpor os limites da tela do computador enquanto espaço de busca de informação para proporcionar um espaço de "construção, de disputa, de contestação de significados" (MOITA LOPES, 2010, p. 398). Essa tentativa pode ser melhor observada na atividade mais extensa do curso, denominada "Hands on: working on a Project" - descrita a seguir e, que ocupou 10 horas, das 40 horas propostas para a semana.

\subsection{Descrição das atividades para produção de Glogsters na English Immersion Week}

Os alunos foram apresentados à plataforma Glogster, que tem por objetivo a criação de pôsteres virtuais a partir do uso de diferentes modalidades de linguagem. O quadro a seguir ilustra como a atividade foi organizada e suas características. 
Quadro 2. Descrição do Hands-on na semana de imersão em inglês

\begin{tabular}{|c|c|}
\hline \multicolumn{2}{|r|}{ Hands-on: Producing a Glogster } \\
\hline Objetivos: & $\begin{array}{l}\text { a) Produzir um poster virtual a partir de um dos temas trabalhados durante a } \\
\text { semana de imersão em inglês. } \\
\text { b) Analisar e sintetizar informações provenientes de diferentes plataformas di- } \\
\text { gitais de acordo com a temática escolhida. } \\
\text { c) Reflitir sobre o uso de diferentes modalidades de linguagem na construção } \\
\text { de sentidos. } \\
\text { d) Articular saberes de diferentes áreas do conhecimento }\end{array}$ \\
\hline Organização & Grupos de 5 alunos \\
\hline Atividades & $\begin{array}{l}1^{\circ} \text { dia - Planejamento para produção do poster virtual do grupo e decisão entre } \\
\text { os participantes dos papéis que cada um assumiria na produção. } \\
2^{\circ} \text { dia - Navegação e reconhecimento da plataforma Glogster e exploração dos } \\
\text { recursos oferecidos. } \\
3^{\circ} \text { dia - Produção de um rascunho do poster virtual e troca de sugestões com } \\
\text { monitores. Busca de recursos onlines para a produção do poster virtual. } \\
4^{\circ} \text { dia - Navegação em outros Glogsters e avaliação de comos os diferentes } \\
\text { recursos semióticos são usados para realização do objetivo de seus produtores. } \\
\text { Avaliação do próprio Glosgter e modificações com base na avaliação. } \\
5^{\circ} \text { dia - Apresentação do poster virtual produzido e publicado para as demais } \\
\text { equipes. }\end{array}$ \\
\hline
\end{tabular}

Como se pode perceber, as atividades foram desenvolvidas de modo a propiciar aos participantes oportunidades de discussão, negociação e avaliação durante a realização da tarefa de produzir um Glogster. A colaboração entre os participantes era fator primordial para o planejamento e produção de um Glogster final que articulasse os conhecimentos discutidos nas oficinas anteriores e as transformações empreendidas pelos participantes para construir significados situados sobre tais conhecimentos.

\subsection{Análise de uma produção de um glosgter: articulações pedagógicas e teóricas}

O texto 1 é uma imagem do Glogster produzido por um dos grupos durante a imersão. $\mathrm{O}$ grupo produziu um poster virtual sobre o uso de redes sociais na Internet. Os participantes articularam discussões realizadas durante as oficinas do eixo temático "Letras" e decidiram pela produção de um poster que enfocasse os lados positivos e negativos do uso de redes sociais. A produção colaborativa dos participantes, nesse exemplo, foi fundamental para a discussão de diferentes perspectivas acerca do uso de redes sociais. Os alunos não só precisaram buscar informações 
sobre redes sociais na Internet como também analisar criticamente as diferentes visões de mundo sustentadas nos textos que encontraram.

As modalidades escrita, visual e sonora foram exploradas pelos alunos na produção do texto 1. A organização das informações em duas colunas, na primeira à esquerda, uso principalmente da modalidade escrita e na segunda à direita, uso principalmente da modalidade visual e sonora, indica a importância a ser dada ao arranjo dos elementos semióticos escolhidos pelos produtores (KRESS, 2010). A informação da primeira coluna é dada como já conhecida por parte do possível leitor (o que justificaria o maior uso da linguagem escrita) e a informação da segunda coluna é apresentada como informação nova para o leitor (o que justificaria o uso de um vídeo para atrair maior atenção do leitor).

Em relação ao uso da língua inglesa, os participantes se engajaram em diferentes leituras de textos sobre o assunto escolhido para decidir quais informações escolher. Os estudantes também se engajaram na escuta de diferentes vídeos para escolher o que melhor se adequava a seus propósitos sóciocomunicativos. Os significados construídos, e as posições assumidas, pelos participantes na produção do Glogster apontam os potenciais de atividades em torno de práticas letradas digitais para aprendizagem situada e interdisciplinar de língua inglesa. A incorporação de diferentes vozes na produção do Glosgter também aponta para o potencial crítico e analítico propiciado pela atividade. 


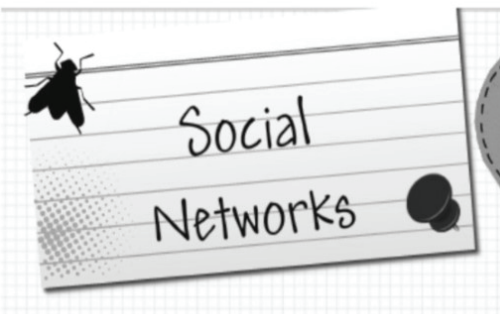

The good and bad things from the social networks...

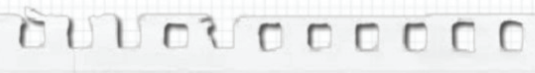

What is it?

A Social Network is a social formation composed by people or organizations, connected for one or many kinds of relations, that share values and goals in common.

There are a lot of kinds of Social Networks for relationships, games, work, and others...

\section{Good things}

You can distract yourself; talk to your family who lives far away; to research; know about your idol's life and share knowledge.

\section{Bad things}

People can take our photos and use them; we can meet people with bad intentions; children can find content unsuitable for their age; lose focus on our tasks; we can click on misleading advertising that can bring viruses to our computer; fall into the hands of the hackers and many other things...

Both good and bad things are daily present in our lifes, and we don't even realize it. Some people show a lot about your personal life without perceiving the danger it brings, they can't see the consequences that will have after posting something inappropriate.
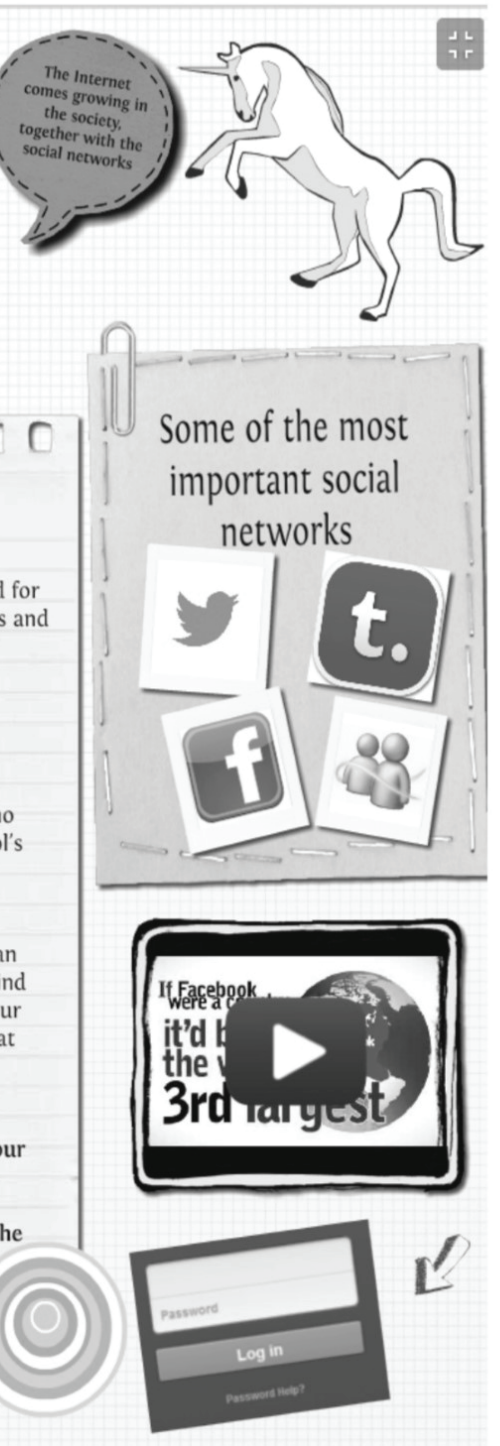

Texto 1. Exemplo de Glogster produzido durante a imersão.

Se, por um lado, a produção de Glosgters propiciou um espaço em que os alunos se engajaram criativa e criticamente na produção de sentidos em práticas letradas digitais situadas e consideraram diferentes vozes para produção de novos 
sentidos; sentidos que eles desejavam atribuir ao tema escolhido (MOITA LOPES, 2010; BUZATO, 2009; SNYDER, 2009), por outro lado, algumas limitações ainda se sobressaem.

Primeiramente, é necessário discutir de que modo a atividade poderia ter propiciado aos participantes mais oportunidades para a discussão e debate de diferentes perspectivas em relação ao tema escolhido. Os produtores do texto 1 decidiram representar em seu Glogster os aspectos bons e ruins do uso de redes sociais. De que modo a atividade poderia ter fomentado visões de mundo mais plurais e complexas, e menos binárias e simples, sobre o tema escolhido e nas decisões de como representá-lo?

Em segundo lugar, mesmo que a atividade proposta e discutida com Glogsters em questão buscasse fomentar a produção de conhecimentos por parte dos alunos a partir do engagemento deles em práticas letradas digitais, há uma séria limitação em termos dos papéis sociais que os alunos assumem e as possibilidades de agência potencializadas pela atividade. De que modo a atividade poderia criar oportunidades para os alunos assumirem identidades sociais mais conectadas a chances de participação social e cidadã? De que modo a atividade poderia ter explorado melhor o uso da prática letrada digital de produção Glogster para a criação de espaços reais de agência e para além das fronteiras da imersão? Acreditamos que essas limitações são de extrema importância e precisam ser repensadas para reelaboração da atividade em questão e para futuras práticas pedagógicas com base em letramentos digitais.

\section{CONSIDERAÇÕES FINAIS}

Neste artigo relatamos como desenvolvemos atividades para aprendizagem de língua inglesa, em um contexto de imersão, ancoradas em pressupostos teóricos sobre letramentos digitais e interdisciplinaridade. Em função dos contextos específicos de formação profissional dos diferentes envolvidos no planejamento e produção das atividades, foi possível observar o uso de diferentes abordagens e/ou métodos, como a comunicativa, a lexical, o Total Physical Response por exemplo, em algumas das atividades.

A proposta relatada se ancorou principalmente em dois pilares. Um deles era a interdisciplinaridade, no intuito de estancar o esvaziamento de práticas pedagógicas isoladas e descontextualizadas e de proporcionar uma aproximação do aluno da escola pública com as possibilidades/oportunidades presentes na universidade. O outro pilar foi o dos letramentos digitais, por meio do uso de ferramentas da web 
2.0, a fim de expandir as possibilidades interacionais dos alunos envolvidos, para fins de aprendizagem e desenvolvimento educacional e participação social em um mundo globalizado e interconectado.

A proposta que apresentamos aponta os potenciais que diferentes práticas letradas digitais podem oferecer para aprendizagem de língua inglesa em contextos de aprendizagem situados e significativos. A cada visita dos alunos aos departamentos diversos e a cada workshop foi possível, por meio de feedback, perceber a conscientização desses alunos em relação ao uso da língua inglesa e da acessibilidade que ela gera. Os temas trabalhados e as atividades propostas forneceram a ponte entre os conhecimentos formais e o uso significativo daquela língua. Além disso, a tentativa de desenvolvimento de um trabalho interdisciplinar encorajou a integração da produção de conhecimentos de diferentes áreas bem como uma apreciação crítica dos diferentes discursos que fundam e constituem tais áreas.

Ressaltamos também a aproximação da universidade com a escola pública, a partir de atividades interdisciplinares e oferecidas em períodos de férias escolares. Tal aproximação foi possível somente porque o programa Novos Talentos, que financiou as atividades, se configurou como um espaço alternativo para formação educacional dos alunos do Ensino Médio. As atividades desenvolvidas mostraram que se provocou nos alunos o desejo de envolvimento com a continuidade acadêmica e com os cursos da universidade, o que parece ser uma direção produtiva.

$\mathrm{O}$ fato de poder visitar diferentes departamentos e utilizar os recursos de diferentes áreas permitiu também uma aproximação interna na universidade. Assim, em relação a implicações desse trabalho, foi possível perceber a necessidade de expansão das relações de trabalho, deixando de contar com os recursos locais, do nosso próprio departamento, e buscar respaldo em outros. Por outro lado, em relação aos conhecimentos, identificamos a necessidade do professor de buscar não apenas fontes autênticas de texto em língua inglesa, mas conhecimentos mais aprofundados sobre os conteúdos trabalhados, de modo a propiciar realmente novos espaços de agentividade para esses alunos.

A necessidade de práticas pedagógicas mais conectadas às demandas contemporâneas, o engajamento dos participantes em práticas letradas digitais e a aprendizagem de língua inglesa a partir de uma perspectiva interdisciplinar foram os desafios que encorajaram o planejamento da experiência relatada. Ao mesmo tempo em que experimentamos novas maneiras de produzir práticas pedagógicas, também questionamos como transformar futuras ações pedagógicas para que sejam mais críticas, agentivas e cidadãs para a aprendizagem de língua inglesa de alunos da rede pública de ensino. 


\section{REFERÊNCIAS BIBLIOGRÁFICAS}

ASHER, J. P. (1969). The total physical response approach to second language learning. Modern Language Journal, v. 53, $\mathrm{n}^{\mathrm{O}}$ 1, pp. 3-17.

BRAGA, D. B. (2010). Tecnologia e participação social no processo e consumo de bens culturais: novas possibilidades trazidas pelas práticas letradas digitais mediadas pela internet. Trabalhos em Linguística Aplicada, Campinas, v. 49, nº 2, pp. 373-391.

BRASIL. (1998). Secretaria de Educação Fundamental. Parâmetros curriculares nacionais: terceiro e quarto ciclos do ensino fundamental: língua estrangeira / Secretaria de Educação Fundamental. Brasília: MEC/SEF.

BRASIL. (2006). Linguagens, códigos e suas tecnologias / Secretaria de Educação Básica, Brasília: Ministério da Educação.

BRASIL. (2012). Diretrizes currriculares nacionais para o Ensino Médio. Resolução n ${ }^{\circ} 2$, de 30 de janeiro de 2012. Ministério da Educação, Conselho Nacional da Educação.

BROWN, D.H. (2007). Teaching by principles: an interactive approach to language pedagogy. 3rd. ed., Pearson ESL, The USA.

BUZATO, M. E. K. (2006). Letramentos digitais e formação de professores. In: III Congresso Ibero-Americano EducaRede, 2006, São Paulo. Anais do III Congresso Ibero-Americano Educarede, São Paulo: CENPEC, pp. 1-7.

BUZATO, M. E. K. (2009). Letramento e inclusão: do estado-nação à era das TIC. Revista de Documentação De Estudos em Linguística Teórica e Aplicada, v. 25, nº 1, pp.1-38.

CASTELlS, M. (2000). A sociedade em rede. São Paulo: Paz e Terra. Tradução de Roneide Venancio Majer, vol. I.

CASTELLS, M. (2005). The network society: from knowledge to policy. In: Castells, M.; Cardoso, G. (org.). The network society: from knowledge to policy. Washington, DC: Johns Hopkins Center for Transatlantic Relations, pp. 3-21. Disponível em: < http://www.umass.edu/digitalcenter/research/pdfs/JF NetworkSociety.pdf $>$ Acesso em: 03/02/2011.

CASTELLS, M. (2007) Communication, Power and counter-power in the network society. International Journal of Communication, California, v.1, pp.238-266.

GAMERO, R.; EL KADRI, M.S.; GIMENEZ, T. (2012). Material didático para educação tecnológica de professores de inglês: uma experiência no âmbito do programa 'Novos Talentos'. Linguagem \& Ensino, Pelotas, v. 15, nº 1, pp. 181-212.

GARCIA, S. C.; LEFFA, V. J. (2010). Percepção e uso da informática pelos professores da área de Letras. Revista Contrapontos, Itajaí, SC., vol. 10, n. 3, out, pp. 327-337. Disponível em: < https://www6.univali.br/seer/index.php/rc/article/view/2034/1724> Acesso em: 14 Jan. 2013.

GEE, J.P. (2004). Situated language and learning: a critique of traditional schooling. New York, London: Routledge.

GRADDOL, D. (2006). English next. British Council. 
KRESS, G. (2010). Multimodality: a social semiotic approach to contemporary communication. New York: Routledge.

KUMARAVADIVELU, B. (2001). Toward a postmethod pedagogy. TESOL Quarterly. 35:4, pp. 537-560

LARSEN-FREEMAN, D. (2000). Techiniques and principles in language teaching. 2nd. ed. New York, US: Oxford.

LEFFA, V. J. (2006). Transdisciplinaridade no ensino de línguas: a perspectiva das Teorias da Complexidade. Revista Brasileira de Lingüística Aplicada, vol. 6, n. 1, pp. $27-49$.

LEU, D.J. ; KINZER, C.K. ; COIRO, J.L. ; CAMMACK, D.W. (2004). Toward a theory of new literacies emerging from the internet and other information and communication technologies. In: Ruddell, R. B.; Unrau, N.J. (ed.). Theoretical models and processes of reading. Newark, DE: International Reading Association, pp. 1570-1613

MARCUSCHI, L.A. (2004) Gêneros textuais emergentes no contexto da tecnologia digital. In: Marcuschi, L.A.; Xavier, A.C. (org.). Hipertexto e gêneros digitais. Rio de Janeiro: Lucerna, pp. 13-90.

MOITA LOPES, L.P. (2005). Inglês no mundo contemporâneo: ampliando oportunidades sociais por meio da educação. Texto-base do Simpósio da TIRF (TESOL International Research Foundation), realizado em São Paulo, mimeo.

MOITA LOPES, L.P. (2010). Os novos letramentos digitais como lugares de construção de ativismo político sobre sexualidade e gênero. Trabalbos em Linguística Aplicada, vol. 49, no 2, jul/dez, pp. 393-417.

NUNAN, D. (1989). Designing tasks for the communicative classroom. Cambridge, UK: Cambridge University Press.

SEVERINO, A.J. (1998). O Conhecimento pedagógico e a interdisciplinaridade: o saber como intensionalização da prática. In: Fazenda, I.C.A. (org). Didática e interdisciplinaridade. Campinas, SP: Papirus, pp. 31-44.

SNYDER, I. (2009). Ame-os ou deixe-os: navegando no panorama de letramentos em tempos digitais. In: Araújo, J. C.; Dieb, M. (org.). Letramentos na Web: gêneros, interação e ensino. Fortaleza: Edições UFC, pp. 23-46.

YOUNG, M. F. D. (2011). O futuro da educação em uma sociedade do conhecimento: a defesa radical de um currículo disciplinar. Cadernos de Educação, Pelotas, vol. 38, jan./ abril, pp. 395-416. Trad. de Helena Beatriz Mascarenhas de Souza.

WILLIS, J. (1996). A framework for task-based learning. Harlow, U.K.: Longman Addison- Wesley.

Recebido: $25 / 09 / 2013$

Aceito: 07/04/2014 